\title{
Prevalence of Tuberculosis-HIV Coinfection and Relationship between Tuberculosis and CD4/ESR in HIV Patients in Niger Delta Region of Nigeria
}

\author{
Nwabuko C.O ${ }^{1}$, Ejele O.A ${ }^{2}$, Chuku A ${ }^{3}$, Nnoli M.A ${ }^{4}$, Chukwuonye I.I ${ }^{5}$ \\ ${ }^{I}$ Department of Haematology Federal Medical Centre Umuahia \\ ${ }^{2}$ Department of Haematology University of Port Harcourt Teaching Hospital \\ ${ }^{3}$ Department of Ophthalmology Federal Medical Centre Umuahia \\ ${ }^{4}$ Department of Histo-Pathology University of Calabar Teaching Hospital \\ ${ }^{5}$ Department of Internal Medicine Federal Medical Centre Umuahia
}

\begin{abstract}
Aim and Objective: One of the major public health challenges globally is the impact of the converging dual epidemics of tuberculosis-HIV coinfection. We aimed to determine the prevalence of tuberculosis-HIV coinfection, and the relationship between tuberculosis and CD4/ESR in HIV patients in Niger Delta region of Nigeria.

Material and method: A total of 389 HIV patients were recruited in the Department of Haematology clinic from January to December 2008. Subjects with clinical features suggestive of tuberculosis performed the following investigations; sputum for AFB examinations, sputum $\mathrm{m} / \mathrm{c} / \mathrm{s}$, Chest $x$-ray, FBC, ESR, tuberculin skin test, and CD4 count. The patients were classified into three groups with respect to CD4, (1, CD41-200. 2, CD4 200-349, and 3, 350-499cells/ul), and into 4 groups with respect to ESR, (1, 0-15. 2, 16-40. 3, 41-99, and 4, $100 \mathrm{~mm} / \mathrm{hr}$ and above.).

Results: The prevalence of tuberculosis-HIV coinfection was $5.91 \%$. Eighteen, 4, and 1 of the tuberculosis patients with regards to CD4, were in group1, 2, and 3 respectively. However, with regards to the ESR, they were all in group 4.

Conclusion:The prevalence of tuberculosis - HIV coinfection is $5.91 \%$ in Niger Delta, and there are relationships between tuberculosis and CD4/ESR in HIV patients.
\end{abstract}

Key Words: Tuberculosis (TB), Human Immunodeficiency Virus (HIV), Acid Fast Bacilli (AFB). CD4 count, Erythrocyte Sedimentation Rate (ESR)

\section{Introduction}

Data from World Health Organization ( WHO) shows that tuberculosis is most common cause of death from infectious diseases, causing more death than HIV and malaria combined; it is common in eastern Europe, south east-Asia and sub-Saharan Africa. One-third of the world is infected with tuberculosis, with Africa harbouring about $29 \%$ of those infected. However only about 5-10\% of those infected develops the disease, and become infectious at some time in their life ${ }^{1}$. Nigeria is one of the countries in sub-Saharan Africa noted to be saddled with a high prevalence of the disease ${ }^{2}$. It is known to have the highest burden of tuberculosis infection in Africa (311per 100,000, about $0.31 \%$ of the population). In a population of 149 million, this implies that about 469,330 people are infected ${ }^{3}$. HIV infection in Nigeria is high; approximately $3.6 \%$ of the population (about 3 million people) are known to be living with HIV infection ${ }^{3}$.

Tuberculosis-HIV coinfection is a problem among patients living with HIIV. The interaction between Tuberculosis and HIV infection is not straight forward. HIV infection being an immunosuppressive disease predisposes patient with latent tuberculosis infection to develop tuberculosis disease. The inmmunosuppression also leads to reactivation of old tuberculosis infection and to previously treated patient being easily re-infected when exposed to a patient with the disease. In tuberculosis-HIV coinfection, the clinical features of tuberculosis are altered due to inmmunosuppression. In patients with high CD4 count (early stage of HIV infection); the clinical features are in keeping with what is generally obtained in none HIV patients. However, in patients with advanced inmmunosuppression, the finding is usually more in keeping with findings in none HIV patients with primary tuberculosis. A majority of those with advanced disease do have lower pulmonary infiltrate, unlike the upper lobe infiltrates seen in none HIV patients. A low percentage may have normal chest radiograph ${ }^{4}$. Tuberculosis - HIV coinfection is classified as AIDS $^{5}$ There are limited studies on the prevalence of tuberculosis-HIV coinfection in Nigeria ${ }^{6}-{ }_{-}^{8}$; moreover, none of the study from Nigeria dealt with the relationship between tuberculosis and CD4/ESR in HIV patients, prompting us to undertake this study. 


\section{Material And Method:}

This is a cross-sectional analysis of baseline data from a prospective, study on the prevalence of tuberculosis-HIV coinfection, among HIV patients in the Niger Delta region of Nigeria. This study was carried out in the Haematology Department clinic of University of Port-Harcourt Teaching Hospital from January to December 2008. Patients diagnosed as having HIV infection attending the clinic were recruited into the study. Those recruited for the study include adults of 18 years and above who have been confirmed as having HIV by Western blot, and are willing to participate in the study. Patients that were pregnant or had malignancies other than Kaposi, those already on antiretroviral drugs, and those who refused to give consent where excluded from the study.

A data acquisition form was used to collect relevant information from the medical history and physical examination of all study subjects. Investigations carried out by the patients that took part in the study include, HIV screening test by ELISA method, HIV confirmatory test by Western blot, (ELISA positive patients performed this test), CD4 count, sputum $\mathrm{m} / \mathrm{c} / \mathrm{s}$, Chest $\mathrm{x}$-ray, tuberculin skin test (A reading of $\geq 5 \mathrm{~mm}$ induration is considered positive for HIV-infected patients' ${ }^{9}$; however in advanced HIV disease with low CD4, there are cases of $<5 \mathrm{~mm}$ reading in tuberculosis-HIV coinfection ${ }^{10}$ ), Full Blood Count, and ESR. All patients suspected of having pulmonary tuberculosis had 3 sputum specimens obtained on 3 consecutive days, and these specimens were examined for AFB.

The estimated sample size is three hundred and ninety patients (390). The patients were divided into three groups based on CD4 count. The first group consist of patients with CD4 of 1- 200cells/ $\mu l$, the second group consist of patients with CD4 of $200-349$ cells/ $\mu l$, while the third group consist of patients with CD4 of 350- 499 cells/ $\mu l$ This grouping is to enable us determine the relationship between tuberculosis and CD4 count. In addition, another classification of the patients into groups based on ESR was made. The patients were classified into 4 groups with respect to ESR, (group 1, 0-15mm/hr, group 2, 16-40 mm/hr, group 3, $41-99 \mathrm{~mm} / \mathrm{hr}$, and $4, \geq 100 \mathrm{~mm} / \mathrm{hr}$.). This grouping was also to enable us determine the relationship between tuberculosis and ESR in HIV patients.

Ethical approval for the survey was obtained from the University of Port Harcourt Teaching Hospital, Ethics Review Committee. Participation in the survey was voluntary and written consent was obtained from participants prior to enrollment after due explanation of the purpose, objectives, benefits and risks of the survey. The data obtained from the study were entered and analyzed using EPI info statistical software version 6.02 . Statistical analysis of mean and standard deviation were calculated. Student $\mathrm{t}$-test was used to test the significance of differences between mean values. A probability (p) less than 0.05 were taken to indicate statistical significance.

\section{Results:}

Three hundred and eighty nine patients took part in the study; however, the estimated sample size was 390 . This implies that the $99.74 \%$ of the estimated sample size took part in the study. The number of women that took part in the study was $248(63.75 \%)$, while the number of men that took part in the study was $141(36.25 \%)$. The age limit was 18years and above. Twenty three of these patients (5.91\%) had pulmonary tuberculosis. 17 of the patients that had tuberculosis were females, while 6 were males. The common presenting symptoms among these patients are shown in table 1.

Table 1; shows the common symptoms of the patients

\begin{tabular}{|lccc|}
\hline Symptoms & Number of Patients & Percentage (\%) & Mean Duration (weeks) \\
\hline Fever & 23 & 100 & 6 \\
Cough & 21 & 91.30 & 4 \\
Weight loss & 19 & 82.61 & 8 \\
Anorexia & 17 & 73.91 & 5 \\
Drenching night sweat & 14 & 68.87 & 5 \\
Haemoptysis & 1 & 4.39 & 2 \\
\hline
\end{tabular}

The $\mathrm{x}$-ray finding in these patients is shown in table 2. The four patients that had a normal chest radiograph all had CD4 of less than 200 cells/ $\mu l$. 
Table 2 Chest $\mathrm{x}$ - ray finding in patients with tuberculosis

\begin{tabular}{|lc|}
\hline Chest x ray findings & Number of patients \\
\hline Pulmonary infiltrates & 16 (upper 3, lower 13) \\
Milliary lesion & 2 \\
Pleural effusion & 1 \\
Cavity lesion & 0 \\
Normal film & 4 \\
\hline
\end{tabular}

Five of the patients had positive sputum examination for AFB, while the rest were negative. The tuberculin reading after 72 hours was $\geq 5 \mathrm{~mm}$ in 17 of the patients. Six, out of 18 patients with CD4 count below 200 cells/ $\mu l$, had tuberculin skin test less than $5 \mathrm{~mm}$. The mean CD4 count for the 389 patients was 206.448 \pm $122.79 \mathrm{cell} / \mu \mathrm{l}$, while the mean CD4 count for the tuberculosis patients was $132.739 \pm 92.493 \mathrm{cells} / \mu l$, the $\mathrm{p}$ value was 0.005 , and this was significant. Table 3 shows the relationship between tuberculosis and CD4 in HIV patients.

Table 3; showing the relationship between tuberculosis and CD4 in HIV patients

\begin{tabular}{|l|l|l|l|}
\hline CD4 group & HIV & TB-HIV coinfection & Total \\
\hline $1-200$ & 183 & 18 & 201 \\
\hline $201-249$ & 122 & 4 & 126 \\
\hline $250-499$ & 61 & 1 & 62 \\
\hline Total & 366 & 23 & 389 \\
\hline
\end{tabular}

Degree of freedom 2, chi square test $7.10, \mathrm{p}$ value 0.287

The mean ESR of 380 of the patients that took part in the study was $103.29 \pm 9.009 \mathrm{~mm} / \mathrm{hr}$, while the mean ESR for the 23 tuberculosis patients was $157.870 \pm 23.085 \mathrm{~mm} / \mathrm{hr}$. The $\mathrm{p}$ value was 0.000 this was significant. Table 4 shows the relationship between tuberculosis and ESR. ESR was obtained from 380 of the patients (nine results of the HIV patients could not be traced). The mean WBC, Platelet, PCV, and BMI of the 389 patients were $5,137 \pm 1,512 \mathrm{cell} / \mathrm{mm}^{3}, 154,002 \pm 84,989 \mathrm{cell} / \mathrm{mm}^{3}, 26.061 \pm 3.587 \%$, and $23.28 \pm 3.42 \mathrm{~kg} / \mathrm{m}^{2}$ respectively.

Table 4; showing the relationship between tuberculosis and ESR in HIV patients

\begin{tabular}{|l|l|l|l|}
\hline ESR group & HIV & TB-HIV coinfection & Total \\
\hline $0-15$ & 9 & 0 & 9 \\
\hline $16-40$ & 35 & 0 & 35 \\
\hline $41-99$ & 106 & 0 & 106 \\
\hline$\geq 100$ & 207 & 23 & 230 \\
\hline Total & 357 & 23 & 380 \\
\hline
\end{tabular}

Degree of freedom 3, chi square test 15.97, and p value was 0.0012 .

\section{Discussion}

The results showed that of the 389 subjects that took part in the study, about $64 \%$ of them were females; while about $36 \%$ were males. Twenty three of the subjects had tuberculosis-HIV coinfection; seventeen of these patients were females, while 6 were males. This gives an observed prevalence of $5.91 \%$ of tuberculosisHIV coinfection in the study group. The prevalence of tuberculosis-HIV infection in the female group is $6.85 \%$, while in the males the prevalence is $4.95 \%$. The result obtained from this study is less than previous prevalence from other studies performed in other parts of the country ${ }^{6-8}$. Surveys carried out in Niger Delta region also reported a higher prevalence of tuberculosis - HIV coinfection ${ }^{11-12}$. We deduce that the decrease in prevalence may be due to the increased awareness of HIV infection, and increase in the number of free treatment centres, provided by the Government and NGO's in the country. More people infected with HIV infection are increasingly assessing the free treatment programme. Early assessment, of the drugs prevents most of them from progressing to the group $1(1-200$ cells/ $\mu \mathrm{l})$ of our CD4 classification. In addition, most centres now commence antiretroviral drugs at a higher CD4 count. Patient in group 1 are more prone to developing tuberculosis - HIV coinfection as shown in table 3.

To evaluate the relationship between tuberculosis and CD4 in HIV patients attending the Haematology clinic, the patients were classified into three groups, as shown in table 3. Group 1 (CD4 count 1-200cells/ $\mu$ ), had a total of 201 subjects, and 18 had tuberculosis - HIV coinfection, group 2 (CD4 count 201- 249 cells/ $\mu$ ), had 126 subjects, and 4 had tuberculosis, while group 3 (CD4 count 250-499 cells/ $\mu$ l) had 62 subjects and only 1 had tuberculosis. The chi square test was 7.10, and the p value was 0.029 and is significant. The result shows 
that there is an inverse relationship between tuberculosis and CD4 count in HIV patients. Our finding is collaborated by another study from the Niger Delta region ${ }^{12}$.

The relationship between tuberculosis and ESR in HIV patients was also one of the factors that were looked into. The twenty three patients that had pulmonary tuberculosis all belonged to the group 4 (ESR $\geq 100 \mathrm{~mm} / \mathrm{hr}$ ). The chi square test was 15.97 , and $\mathrm{p}$ value was 0.00115 , and is significant. This showed a direct relationship between tuberculosis and ESR. It also strongly suggest that most patients with HIV, that have cough of more about 4 weeks, and with an ESR of more $\geq 100 \mathrm{ml} / \mathrm{hr}$ are more likely have pulmonary tuberculosis.

\section{Conclusion}

This study showed that the prevalence of tuberculosis - HIV coinfection is $5.91 \%$ in the Niger Delta region of Nigeria. The study also showed an inverse relationship between tuberculosis and CD4, and direct relationship between tuberculosis and ESR in HIV patients. The entire patient with pulmonary tuberculosis had an ESR of $\geq 100 \mathrm{~mm} / \mathrm{hr}$; this suggests that ESR could be used as a predictive marker of tuberculosis-HIV coinfection.

\section{Limitation}

We lacked facilities for culture, which is needed for accurate diagnosis of mycobacterium tuberculosis in those patients identified as having positive AFB smear results. A positive sputum AFB, is not diagnostic of mycobacterium tuberculosis, because the stain detects other strains of mycobacterium e.g. M. avium intracellulare, However, this limitation, do not invalidate our study.'

\section{Conflict of interest}

The authors which to state that there is no conflict of interest in this research. The research was not funded by any organization.

\section{References:}

[1] World health science- tuberculosis worldwide statistics and infectious rate. http://www.worldhealthsciences.com/tuberculosistb.html

[2] Egah TE, Okoli CU. Tuberculosis in Jos Nigeria: A 9 year Review of Laboratory Report at Jos University Teaching Hospital (JUTH). Nigeria Med Pract. 2004; 46: 36-46

[3] HIV/AIDS and Tuberculosis coinfection. USAID/Nigeria. nigeria.usaid.gov/programs/hivaids-and-tuberculosis

[4] Post FA, Wood R, Pillay GP. Pulmonary tuberculosis in HIV infection: radiographic appearance is related to CD4+ T-lymphocyte count. Tubercle and Lung Dis 1995;76:518-21.

[5] From the Centers for Disease Control and Prevention. 1993 revised classification system for HIV infection and expanded surveillance case definition for AIDS among adolescents and adults. JAMA 1993; 269:729.

[6] Iliyasu Z, Babashani M. Prevalence and predictors of tuberculosis coinfection among HIV-seropositive patients attending the Aminu Kano Teaching Hospital, northern

[7] Nigeria. J Epidemiol. 2009;19(2):81-7

[8] Salami AK, Katibi IA. Human immunodeficiency virus-associated tuberculosis: pattern and trend in the University of Ilorin Teaching Hospital. Afr J Med Med Sci. 2006 Dec;35(4):457-60.

[9] Pennap G, Makpa S, Ogbu S. Sero-prevalence of HIV infection among tuberculosis patients in a rural tuberculosis referral clinic in northern Nigeria. Pan Afr Med J. 2010 Jun 21;5:22

[10] Centers for Disease Control and Prevention. Targeted tuberculin testing and treatment of latent tuberculosis infection. Morb Mortal Wkly Rep 2000;49:1-51.

[11] Markowitz N, Hansen N, Wilcosky T, et al. Tuberculin and anergy skin testing in HIV seropositive and HIV seronegative persons. Ann Intern Med 1993;119:185-93.

[12] Affusim CC, Kesieme E, Abah VO. The Pattern of Presentation and Prevalence of Tuberculosis in HIV-Seropositive Patients Seen at Benin City, Nigeria. ISRN Pulmonology. Volume 2012, Article ID 326572, 6 pages

[13] Azuonwu 0, Putheti R, Amadi F, Obire O. Prevalence of Tuberculosis in HIV infected patients. Journal of Advanced Pharmacy Education \& Research1:1-11 (2011) 